\title{
ASSOCIATIVISMO, ESFERAS PÚBLICAS SUBALTERNAS E COVID-19: REDES DE SOLIDARIEDADE SOCIAL E RESISTÊNCIA POLITICA
}

ASSOCIATIVISM, SUBALTERN PUBLIC SPHERES, AND COVID-19: NETWORKS OF SOCIAL SOLIDARITY AND POLITICAL RESISTANCE

Fernando Perlatto

Doutor em Sociologia pelo Instituto de Estudos Sociais e Políticos da Universidade do Estado do Rio de Janeiro (IESP/UERJ) e professor do Departamento de História e do Programa de Pós-graduação em História da Universidade Federal de Juiz de Fora (UFJF). 


\section{RESUMO}

Este artigo objetiva analisar espaços de associativismo e redes de solidariedade social que foram organizadas no Brasil durante a pandemia da Covid-I9. Além de refletir sobre essas diferentes experiências que evidenciam a capacidade associativa de diferentes setores - e que contribuem com a problematização do "mito do insolidarismo social" no Brasil -, este artigo busca pensar essas redes de solidariedade social a partir do conceito de "esferas públicas subalternas", destacando suas potencialidades como espaços de resistência política.

Palavras-chave: Covid-I9; associativismo; redes de solidariedade social; esferas públicas subalternas; resistência política.

\section{ABSTRACT}

This article aims to analyze spaces of associativism and networks of social solidarity that were organized in Brazil during the Covid-I9 pandemic. In addition to reflecting on these different experiences that show the associative capacity of different sectors - and that contribute to the problematization of the "myth of social insolidarism in Brazil" -, this article seeks to reflect upon these networks of social solidarity based on the concept of "subaltern public spheres", highlighting their potential as spaces of political resistance.

Keywords: Covid-ı; associativism; networks of social solidarity; subaltern public spheres; political resistance. 


\section{Introdução}

Compreender os impactos sobre a humanidade desencadeados por uma pandemia com as proporções da Covid-I9 não é tarefa fácil. Desde o início de 2020 , quando as primeiras notícias começaram a circular de que o vírus havia se espalhado por diferentes continentes, em uma velocidade muito mais vertiginosa e destrutiva do que poderia se prever, diversas obras têm sido publicadas com o intuito de analisar os desdobramentos da pandemia em diferentes áreas da vida social. Paralelamente ao trabalho notável levado adiante por profissionais da saúde, epidemiologistas e especialistas da área, no sentido de desenvolverem protocolos de prevenção, insumos, equipamentos, vacinas e novos medicamentos para se reduzir os impactos do coronavírus, diversos analistas do campo das ciências humanas vêm buscando compreender quais têm sido e quais serão as principais consequências políticas, sociais, econômicas e culturais da Covid-ı9 nos âmbitos local, nacional e internacional.

Em torno dessa agenda reflexiva, várias obras têm sido lançadas ao longo dos últimos meses. No Brasil, em particular, além da publicação de livros como O futuro começa agora: da pandemia à utopia, de Boaventura de Souza Santos; e Notas sobre a pandemia: e breves lições para o mundo pós-coronavírus, de Yuval Noah Harari; algumas editoras lançaram coleções dedicadas exclusivamente para este fim, a exemplo da Todavia, que, no âmbito da "Coleção 2020. Ensaios sobre a pandemia", publicou obras como Curto-circuito. O vírus e a volta do Estado, de Laura Carvalho; e Três pragas do vírus: política internacional, dívida e desemprego na pandemia, de Vinícius Torres Freire; e a editora Boitempo, que publicou a série "Pandemia capital", a exemplo de Pandemia: Covid-I9 e a reinvenção do comunismo, de Slavoj Zizek; Reflexões sobre a peste: ensaios em tempos de pandemia, de Giorgio Agamben; Construindo movimentos: uma conversa em tempos de pandemia, de Angela Davis e Naomi Klein; e Anticapitalismo em tempos de pandemia: marxismo e ação coletiva, de David Harvey.

Em relação às reflexões realizadas sobre os impactos da pandemia na vida social, um dos diagnósticos mais correntes no início da pandemia, ainda nos primeiros meses de 2020, era o de que os danos causados pela Covid-ı, para além de suas óbvias dimensões negativas, poderiam deixar legados importantes no sentido de fazerem com que as pessoas, diante das dificuldades individuais e coletivas impostas pelo coronavírus, passassem a valorizar outros aspectos de suas vidas cotidianas, buscando o fortalecimento de laços de solidariedade social. A despeito das medidas de isolamento, a pandemia poderia contribuir para um deslocamento do "eu" ao estimular sentimentos de preocupação mútua, de cooperação e de ajuda ao próximo. A ideia subjacente a essas leituras esperançosas era a de que as pessoas se tornariam menos egoístas, menos autocentradas e menos individualistas. E, a princípio, de fato, nos momentos iniciais da pandemia, até ocorreram vários movimentos nesse sentido, a exemplo 
da ampliação de doações para pessoas em condições de vulnerabilidade social, e de manifestações de solidariedade internacional a países mais fortemente atingidos pelo coronavírus, como foi o caso da Itália.

Mas, à medida que a pandemia foi avançando ao longo dos meses, atingindo mais fortemente diferentes países, as perspectivas mais otimistas foram cedendo espaço para a percepção de que não apenas o novo contexto aberto pelo coronavírus não iria fortalecer laços de solidariedade social, mas, pelo contrário, agravaria o atual cenário hobbesiano de guerra de todos contra todos. A redução, ao longo do tempo, da pressão em diferentes países por medidas direcionadas para a ampliação do auxílio às populações mais vulneráveis socialmente e o acesso desigual às vacinas em âmbito internacional - que resulta no fato de os países desenvolvidos terem doses suficientes para vacinarem quase toda a sua população, inclusive grupos que não são considerados prioritários, ao passo que muitas nações subdesenvolvidas ainda estão dando os passos iniciais no processo de vacinação - são apenas algumas das facetas mais perversas a evidenciarem a lógica na qual os valores da solidariedade social passaram a ser secundarizados tanto em âmbito nacional, quanto internacional.

Porém, a despeito dessas manifestações de individualismo que têm se expandido ao longo dos últimos meses, é possível também testemunhar, durante a pandemia, iniciativas e movimentos que caminham em uma direção contrária, marcados justamente pelo surgimento e/ou pela ampliação de experiências de cooperação e de constituição de redes de solidariedade social. Em uma perspectiva alternativa ao egoísmo hegemônico exacerbado, é possível observar, em diferentes países, setores que se organizam, que se mobilizam e que se associam, muitas vezes sem quaisquer mediações do Estado, constituindo laços de cooperação e de solidariedade com notável criatividade, dinâmica, força e permanência. Muitas dessas experiências societais têm se configurado como manifestações concretas ou embriões em potencial daquilo que, em diálogo com autores da teoria crítica, em especial Jürgen Habermas, Nancy Fraser e Craig Calhoun, tenho chamado de "esferas públicas subalternas" (PERLATTO, 20I8).

O objetivo deste artigo é precisamente analisar algumas experiências de associativismo que vêm tendo curso em meio à pandemia da Covid-I9, com o intuito de refletir sobre suas potencialidades para a constituição de redes de solidariedade social e para sua conformação como espaços de resistência política na atual conjuntura. Para desenvolver esse argumento, o texto está dividido em duas seções. Na primeira parte, ainda que sem quaisquer pretensões de generalizações, busco realizar um mapeamento de três tipos de experiências de associativismo que vêm tendo curso no Brasil ao longo dos últimos meses, em diferentes áreas da vida social. Ressalta-se a organização desses espaços cooperativos e dessas redes de solidariedade social que vêm se constituindo e se estabelecendo "por baixo", protagonizadas 
sobretudo por setores periféricos. Na segunda seção do texto, partindo dessas experiências, procuro refletir teoricamente sobre esses espaços e essas redes de solidariedade, mobilizando, para tal, o conceito de "esferas públicas subalternas" com o intuito tanto de destacar de que maneira elas contribuem para problematizar o "mito do insolidarismo social" brasileiro, quanto de destacar as potencialidades dessas redes de solidariedade social para a organização de novos espaços de resistência política no país.

\section{Brasil: associativismo e redes de solidariedade social em meio à pandemia}

Desde o momento inicial em que pandemia aportou no país, o Brasil tem sido pródigo em exemplos de manifestações perversas de individualismo e de egoísmo de setores diversos que caminham em direção contrária aos valores de solidariedade social, cooperação e interesse público. Situações como a dos empresários do setor de transportes, em Minas Gerais, que tentaram fraudar o Plano Nacional de Imunização (PNI), se somam a tantas outras - como a organização de festas clandestinas por todo o país e a atuação de empresários junto ao Congresso Nacional para que a iniciativa privada pudesse comprar vacinas sem contrapartida de doação de doses para o Sistema Único de Saúde (SUS) -, que evidenciam justamente a proliferação de comportamentos caracterizados pela sobreposição da dimensão do "eu" sobre a ideia de "nós" e a secundarização de quaisquer valores mais coletivos de solidariedade social, de cooperação e de interesse público.

Porém, a despeito de comportamentos individualistas e egoístas, também é possível observar na sociedade brasileira a organização de iniciativas que configuram experiências potentes de constituição de redes de solidariedade social, as quais foram organizadas ou ampliadas durante a pandemia da Covid-I9. Para deixar mais claro o argumento que pretendo desenvolver aqui, vou concentrar a análise nesta seção do texto em três tipos de experiências de redes de solidariedade social, organizadas em diferentes áreas e esferas da vida social, que evidenciam a potência associativa de setores diversificados da sociedade brasileira. A maior parte dessas redes de cooperação social tem se formado e se estabelecido em regiões periféricas, "por baixo" e "por fora" dos espaços tradicionais da política, e maior grau sem apoios ou mediações mais sistemáticas por parte do Estado, a partir da constituição de espaços organizativos que vêm reunindo, agregando e mobilizando milhares de pessoas no país.

Antes de mencionar e examinar os tipos de experiências associativas selecionadas para a análise, é importante deixar claro duas ideias que ancoram o argumento proposto neste artigo. Em primeiro lugar, não há aqui qualquer pretensão de dizer que essas redes de solidariedade social são os exemplares mais significativos desses tipos de espaços de associativismo que têm se constituído na sociedade brasileira. Trata-se tão-somente de 
mobilizá-las como exemplos potentes e significativos de redes de cooperação social que vêm sendo organizadas ou ampliadas em meio à pandemia da Covid-I9. Em segundo lugar, vale também ressaltar que não se tem neste artigo o objetivo de idealizar essas experiências de associativismo, identificando nelas apenas elementos virtuosos e positivos. É claro que essas formas coletivas de organização têm também contradições, limites e problemas. Mas o que se busca é apenas identificar as existências dessas experiências, com o intuito de destacar que, paralelamente ao individualismo hegemônico, é possível também perceber a presença de iniciativas de cooperação e ressaltar suas potencialidades como espaços de conformação de redes de solidariedade social e de organização da resistência política.

Feitas essas ressalvas, é possível avançar no argumento e descrever os três tipos de experiências associativas que evidenciam essa potência cooperativa de setores da sociedade brasileira, organizadas e/ou ampliadas no contexto da pandemia.

Em primeiro lugar, algumas das experiências de redes de solidariedade social mais potentes que têm sido organizadas na sociedade brasileira, ao longo dos últimos meses, são aquelas direcionadas para a construção de respostas comunitárias para o enfrentamento do coronavírus. A maior parte dessas experiências tem sido constituídas sobretudo em periferias e favelas espalhadas por todo o país. Conforme diferentes estudos vêm demonstrando - a exemplo da nota técnica publicada pela Fiocruz sobre os impactos da Covid-I9 nesses territórios ${ }^{1}$-, as condições de vulnerabilidade social desses espaços periféricos, que apresentam uma infraestrutura pública mais precarizada, se agravaram significativamente durante a pandemia, em decorrência da alta densidade demográfica, da existência de habitações precárias, das dificuldades de acesso à água, ao encanamento, à coleta de lixo, à moradia digna, aos insumos básicos de saúde, do maior deslocamento das pessoas que habitam nesses lugares para o local de trabalho em transportes públicos, além de uma maior concentração de populações que, em decorrência da ausência histórica de serviços públicos essenciais, apresenta maiores vulnerabilidades nas condições de saúde.

Apesar dessas dificuldades, é possível perceber em várias dessas comunidades periféricas - como em Paraisópolis, em São Paulo; ou em favelas e territórios precarizados do Rio de Janeiro, como Complexo do Alemão, Maré, Manguinhos e Baixada Fluminense experiências de constituição de redes de solidariedade social que evidenciam uma enorme capacidade de auto-organização para o enfretamento coletivo da pandemia. Impulsionadas, na maior parte das vezes, por lideranças comunitárias, e contando com amplo apoio de voluntários da própria comunidade - além da articulação com organizações governamentais

\footnotetext{
${ }^{1}$ Disponivel em: <https://portal.fiocruz.br/sites/portal.fiocruz.br/files/documentos/nota_tecnica_-_enfrentar_covid19_com_protea_a_o_social_28-05-20.pdf >. Acesso em: 20 abr. 2021.
} 
e não governamentais externas a esses territórios -, essas redes estimulam iniciativas de conscientização dos moradores sobre medidas de prevenção da Covid-I9, mediante a utilização de carros de som, cartazes e rádios comunitárias locais; contratação de ambulâncias, realização de testes, monitoramento e isolamento social de pessoas enfermas; e organização de campanhas de arrecadação de recursos, produtos de limpeza, álcool em gel, sabão e cestas básicas nas redes sociais e junto à iniciativa privada, resultando em experiências concretas de solidariedade comunitária para o combate ao vírus. ${ }^{2}$

Uma ação que evidencia a força dessas redes de solidariedade social foi aquela que ocorreu no início de 202I e que resultou na criação, no estado do Rio de Janeiro, do Dia Estadual de Mobilização para Enfrentamento da Covid-I9 e seus Impactos nas Favelas e Periferias, ou \#MobilizaFavela. Coordenado por coletivos e organizações diversas, como Rocinha Resiste, Frente CCD Contra a Covid-I9, Grupo Eco, Instituto Raízes em Movimento e Redes da Maré, o movimento realizou atividades de prevenção e de conscientização relacionadas à pandemia em favelas e periferias do estado, mediadas pelos moradores dessas comunidades. ${ }^{3}$ É interessante destacar que o estabelecimento do dia Io de fevereiro como data oficial para a mobilização foi aprovado na Assembleia Legislativa (RJ) e passou a fazer parte do calendário oficial do estado. O Projeto de Lei no 9.I86/202 I, de autoria da deputada estadual Mônica Francisco (PSOL), em articulação direta com movimentos sociais de favelas, teve como objetivo principal "ampliar a participação social na vigilância em saúde de base territorial e promover a proteção social específica das favelas e periferias, promovendo ações integradas entre a Administração Pública, as Universidades Públicas, a sociedade civil e os movimentos sociais". ${ }^{4}$

Um segundo exemplo de redes de solidariedade social que vêm sendo constituídas no país são aquelas direcionadas à arrecadação e à distribuição de alimentos para pessoas em condições de vulnerabilidade social, sobretudo em comunidades populares. De acordo com o Inquérito Nacional sobre Insegurança Alimentar no Contexto da Pandemia da Covid-ı9 no Brasil, conduzido pela Rede Brasileira de Pesquisa em Soberania e Segurança Alimentar e Nutricional (Rede Penssan), realizado nas cinco regiões do país em áreas urbanas e rurais, nos últimos meses de 2020, $9 \%$ da população, ou seja, I9 milhões de brasileiros passaram

\footnotetext{
${ }^{2}$ Sobre a organização de Paraisópolis para o enfrentamento da pandemia, ver, entre outros: <https:/g1.globo.com/fantastico/noticia/2020/12/27/rede-de-solidariedade-transforma-paraisopolis-em-meio-apandemia.ghtml>. Acesso em: 22 abr. 2021.

Sobre a organização de favelas e comunidades no Rio de Janeiro, ver, entre outros: <https://www.uol.com.br/ecoa/ultimasnoticias/2020/04/24/sem-estado-favelas-do-brasil-criam-proprias-solucoes-para-encarar-pandemia.htm> . Acesso em: 21 abr. 2021.

${ }^{3}$ Sobre o tema, ver, entre outros: <https://rioonwatch.org.br/?p=53566>. Acesso em: 25 abr. 2021.

${ }^{4}$ Para acesso ao Projeto de Lei, ver:

<http://alerjln1.alerj.rj.gov.br/scpro1923.nsf/02ac6f279b568e24832566ec0018d839/0bd32b049d30049a03258671006b7ba7 ?OpenDocument\&CollapseView>. Acesso em: 26 abr. 2021.
} 
fome e mais de $50 \%$ enfrentou algum grau de insegurança alimentar, que representa um aumento de $55 \%$ em relação a $2018 . .^{5}$ Como resposta a esse cenário, o que se tem visto em diferentes cidades do país, sobretudo nas periferias, é a organização de redes de solidariedade social para a distribuição de alimentos, impulsionadas por movimentos sociais, grupos religiosos, associações de bairro e lideranças comunitárias - a exemplo das campanhas Mães de Favela; ${ }^{6}$ Corona no Paredão, Fome Não; ${ }^{7}$ e Tem Gente Com Fome, Dá De Comer, ${ }^{8}$ organizadas respectivamente pela Central Única das Favelas (CUFA), pela Rede Gerando Falcões e pela Coalizão Negra por Direitos - que buscam arrecadar cestas básicas para serem distribuídas a famílias em condições de vulnerabilidade social.

Dentre as mais recentes iniciativas em resposta à situação de insegurança alimentar agravada pela pandemia, destacam-se as Cozinhas Solidárias, organizadas pelo Movimento dos Trabalhadores Sem-Teto (MTST). ${ }^{9}$ Lançadas no início de $202 \mathrm{I}$, e ancoradas na arrecadação de alimentos e de doações realizadas mediante financiamento coletivo na internet, as Cozinhas Solidárias objetivam angariar recursos e apoios para inaugurar cozinhas comunitárias nas periferias de centros urbanos brasileiros. Além da distribuição de refeições completas e balanceadas, elaboradas a partir da ideia do direito à alimentação saudável e nutritiva, o projeto contribui com o estímulo a hortas urbanas comunitárias nas periferias, que fornecem parte dos alimentos empregados para a produção das marmitas. Essa experiência é um grande exemplo da potência e da capilaridade dessas de redes de solidariedade social voltadas para a arrecadação e distribuição de alimentos para pessoas em condições de vulnerabilidade social.

Uma terceira experiência de constituição de redes de solidariedade social impulsionadas no contexto da pandemia são aquelas relacionadas à organização coletiva dos trabalhadores do mercado informal, sobretudo de entregadores de aplicativos. Desde o início da pandemia, sobretudo em decorrência das medidas de isolamento social estabelecidas por governos municipais e estaduais, os gastos com aplicativos de entrega, como iFood, Rappi e Uber Eats, cresceram mais de 90\%. ${ }^{10}$ Apesar da ampliação expressiva da demanda por esses serviços de plataforma digital, o movimento não obteve impactos mais significativos no aumento dos salários e na melhoria das condições de trabalho dos entregadores, que não apenas permaneceram

\footnotetext{
${ }^{5}$ Para mais informações: <http://olheparaafome.com.br/> . Acesso em: 26 abr. 2021.

${ }^{6}$ Sobre o projeto Mães de Favela, ver: <https://www.maesdafavela.com.br/> . Acesso em: 27 abr. 2021.

${ }^{7}$ Sobre o projeto Corona no Paredão, Fome Não, ver: <https://gerandofalcoes.com/>. Acesso em: 27 abr. 2021.

${ }^{8}$ Sobre o projeto Tem Gente Com Fome, Dá De Comer, ver: <https://www.temgentecomfome.com.br/>. Acesso em: 27 abr. 2021.

${ }^{9}$ Sobre o projeto das Cozinhas Solidárias, ver: <https://apoia.se/cozinhasolidaria?fbclid=IwAR1D4PdyphGUHWhdfqrTliOrfrvBIOEioHOJuCBUHPoOh2j0NNEORFPBf0>. Acesso em: 29 abr. 2021.

${ }^{10}$ Ver, entre outros: <https://www.idinheiro.com.br/gastos-com-delivery-crescem-durante-pandemia/>. Acesso em: 15 abr. 2021.
} 
estruturalmente precarizados, mas que foram significativamente agravados durante a pandemia, em decorrência da sobrecarga de trabalho e da redução na remuneração, em decorrência da ampliação do número de trabalhadores cadastrados e da redução do valor pago pelas plataformas digitais pela hora trabalhada. ${ }^{11}$

As manifestações que ocorreram em julho de 2020 em diversas cidades do país, que ficaram conhecidas como Breque dos Apps, organizadas por entregadores de aplicativos justamente para reivindicar aumento nos valores de pagamento para as rotas realizadas e melhores condições de trabalho, incluindo equipamentos de proteção, como máscaras e álcool em gel, foram inciativas importantes para a conformação de novos laços de solidariedade social. ${ }^{12}$ Ainda que o movimento seja um pouco difuso e incipiente, ele aponta não apenas para ações importantes que vêm ocorrendo em âmbito internacional - voltadas para a regulamentação dos direitos de trabalhadores do mercado informal de grandes empresas da chamada gig economy, como Uber e iFood -, mas também sinaliza para as potencialidades organizativas e associativas de trabalhadores precarizados, que buscam, apesar de todas as dificuldades, construir espaços de sociabilidade e pautar suas reivindicações, muitas vezes fora dos espaços clássicos de organização dos trabalhadores formais, como os sindicatos.

Após analisar essas três experiências de constituição de redes de solidariedade social, relacionadas quer seja ao enfrentamento comunitário da Covid-ı, quer seja à arrecadação de alimentos, ou ainda à organização de trabalhadores informais precarizados, é possível afirmar que, apesar das práticas hegemônicas de individualismo e de egoísmo durante a pandemia, tem havido no Brasil movimentos importantes que caminham na direção da solidariedade. Na próxima seção, em diálogo com o conceito de "esferas públicas subalternas", destaco de que maneira essas experiências de associativismo e de cooperação contribuem no sentido da problematização do "mito do insolidarismo social" brasileiro e procuro chamar atenção para as potencialidades dessas redes de solidariedade social para a conformação de espaços de resistência política na atual conjuntura do país.

\section{Associativismo, "esferas públicas subalternas" e resistência política}

Determinadas ideias são tão compartilhadas pelas pessoas que, por serem repetidas seguidas vezes, viram quase um "senso comum", no sentido de que são naturalizadas sem

\footnotetext{
${ }^{11}$ Dsponível em: <https://www.cesit.net.br/wp-content/uploads/2020/06/74-Texto-do-artigo-568-2-10-20200608.pdf>. Acesso em: 15 abr. 2021.

12 Sobre o Breque dos Apps, ver, entre outros: <https://brasil.elpais.com/opiniao/2020-07-27/greve-dos-entregadores-escancaroua-falacia-da-economia-do-compartilhamento.html>. Acesso em: 15 abr. 2021.
} 
grandes problematizações. Exemplar nesse sentido é a formulação de que a sociedade brasileira, sobretudo quando comparada com os países do centro do capitalismo, teria como principais características a apatia, a desorganização, a desmobilização e a incapacidade de construir espaços de sociabilidade e de articular redes de solidariedade social mais amplas. Em termos acadêmicos, o povo brasileiro, segundo essa interpretação compartilhada por muitos segmentos, não teria "capital social", para dialogar com os termos de Robert Putnam (I996), elemento necessário para a construção de ações coletivas e colaborativas duradouras e de mais largo alcance. É precisamente esse tipo de leitura da sociedade brasileira, atravessada pela tibieza associativa e pelo raquitismo cívico, que deu base, por exemplo, para a ideia do "gigante adormecido", o qual teria subitamente acordado nas manifestações de junho de 2013 que tomaram as ruas de várias cidades do país.

Essa interpretação corrente no "senso comum" apresenta uma longeva tradição no campo do pensamento social brasileiro. Uma das suas fontes originais é a obra de Oliveira Viana, em especial Populações Meridionais do Brasil (1920), na qual o autor formula com mais sistematicidade as bases do "mito do insolidarismo social brasileiro". Esse tipo de leitura da sociedade brasileira - que estará também presente, ainda que com particularidades próprias, nas obras dos chamados "pensadores autoritários" dos anos 1930, como Alberto Torres e Francisco Campos, inclusive como forma de legitimar o discurso em defesa de uma intervenção "por cima" de um de um Estado forte, capaz de organizar e vertebrar essa sociedade naturalmente insolidária - está presente, de diferentes maneiras, em outras interpretações do Brasil. Seja na perspectiva das chamadas teorias do populismo ou do patrimonialismo - que defendem a ideia de que a presença de um Estado forte ao longo da história teria atrapalhado o desenvolvimento autônomo da sociedade civil no país -, seja na perspectiva de abordagens mais culturalistas - que identificam na cultura, herdada de Portugal, traços de privilégio das relações privatistas, em detrimento de valores relacionados à solidariedade, ao coletivo e ao bem público -, o que se vê é a presença constante de leituras que se aproximam quanto ao diagnóstico da ausência ou da tibieza do associativismo no Brasil, reforçando o "mito do insolidarismo" nacional.

Apesar da força dessa interpretação no "senso comum" e no pensamento social brasileiro, é necessário problematizá-la e desnaturalizá-la com o intuito de ampliar e tornar mais complexa a reflexão sobre os espaços de associativismo e de sociabilidade da população ao longo da história e no tempo presente. Em diálogo com a produção historiográfica brasileira dedicada aos estudos dos trabalhadores - que, ancorada sobretudo nas obras de Edward E. Thompson, em especial A formação da classe operária inglesa, vêm problematizando o "paradigma da ausência" e afirmando um "paradigma da agência" dos "de baixo" (CHALHOUB; SILVA, 2009) - e com produções das ciências sociais relacionadas aos espaços 
de associativismo mais contemporâneos de setores subalternos na sociedade brasileira, venho buscando em meus trabalhos destacar que, longe de uma sociedade apática e desmobilizada, o que temos no Brasil são segmentos que se organizam, se mobilizam e que constituem redes plurais e diversas de solidariedade social (PERLATTO, 2015). Para compreender esses espaços organizativos, venho sugerindo o conceito de "esferas públicas subalternas", que, de acordo com minha leitura, auxilia na compreensão conceitual dessas diferentes experiências de associativismo e de constituição de redes de solidariedade social que vêm se organizando na sociedade brasileira ao longo dos anos (PERLATTO, 2OI8).

O conceito de "esferas públicas subalternas" é formulado em diálogo direto com as críticas que foram elaboradas à categoria de "esfera pública", proposta originalmente por Jürgen Habermas, em sua clássica obra de 1962, Mudanças estruturais da esfera pública (HABERMAS, 20I4). A problematização formulada por Nancy Fraser (1992), em particular, me interessa mais diretamente, na medida em que ela procura demonstrar que, ao focar sua análise na "esfera pública burguesa", Habermas teria deixado de perceber a existência de outras esferas que teriam se organizado "por fora", em espaços informais, por setores excluídos, como mulheres e operários, que ela chama de subaltern counterpublics. ${ }^{13}$ Porém, ainda que a proposição de Fraser me interesse no sentido de provocar um olhar para esses espaços que se organizam "por fora" da esfera pública burguesa, seu conceito de subaltern counterpublics me parece equivocado por duas razões: em primeiro lugar, a ideia de counterpublics sugere que esses públicos subalternos são necessariamente contrários à esfera pública burguesa, o que nem sempre é verdade. As relações estabelecidas entre essas esferas, mesmo desiguais e marcadas por relações assimétricas de poder, são muito mais complexas e caracterizadas por aquilo que Carlo Ginzburg (1998), em diálogo com Mikhail Bakhtin, chamou de "circularidade cultural", com cada qual filtrando determinados elementos da outra, a partir dos próprios valores, dinâmicas e experiências. Em segundo lugar, em diálogo com a primeira crítica, o conceito de counterpublics de Fraser sugere que essas esferas subalternas apenas existem em decorrência da esfera pública burguesa, como se elas não tivessem autonomia e apenas pudessem existir exclusivamente para se contraporem à esfera pública burguesa.

\footnotetext{
${ }^{13}$ Outros autores formularam críticas semelhantes à formulação de Habermas em torno da esfera pública burguesa. Na obra Public sphere and experience: toward and analysis of the bourgeois and proletarian public sphere, de Oscar Negt e Alexander Kluge, publicada originalmente em 1972, os autores propõem o conceito de "esfera pública proletária", que, ao contrário de suas congêneres burguesas, aprisionadas à consciência individualista e racionalista, teria se constituído principalmente a partir da experiência concreta e diária dos atores sociais (NEGT; KLUDGE, 1993). Elley (1992), Landes (1988) e Squires (2002) destacam em seus trabalhos, respectivamente, o fato de Habermas secundarizar questões étnicas, de gênero e raciais em suas reflexões sobre a esfera pública burguesa. Para uma discussão bibliográfica sobre o tema, ver Perlatto (2018, p. 158-167).
} 
Partindo desse diálogo crítico com Habermas e Fraser - e incorporando para a análise também outros autores que buscam pensar a categoria de esfera pública em uma perspectiva associada à teoria crítica, como Michael Warner (2002) e Craig Calhoun (2012) -, tenho proposto o conceito de "esferas públicas subalternas" para analisar precisamente a formação desses espaços de associativismo e de constituição de redes de solidariedade social que vêm sendo construídos "por baixo" na sociedade brasileira, e que, importa destacar, não necessariamente se confundem com movimentos sociais organizados. Nesse sentido, vale também ressaltar que a formulação do conceito de "esferas públicas subalternas" estabelece um diálogo direto com autores da teoria pós-colonial, sobretudo dos chamados subaltern studies, especialmente Gayatri Spivak (1988), que chamam atenção para a importância de olhar para os espaços organizativos dos setores subalternos nos países periféricos e semiperiféricos, como o Brasil, a partir das próprias lógicas e dinâmicas, sem ter como modelos ou tipos ideais aqueles espaços de sociabilidade constituídos nos países do centro do capitalismo. No caso específico do Brasil, sobretudo em decorrência das particularidades da nossa história e da "seletividade da esfera pública burguesa" - marcada pela exclusão de amplos setores analfabetos da participação política -, os espaços de sociabilidade, de organização e de solidariedade social constituídos "por baixo" adquiriam formas mais lúdicas, carnavalescas e expressivistas, as quis são marcas importantes da cultura popular nacional.

O reconhecimento da existência dessas "esferas públicas subalternas" não deve, porém, levar à idealização desses espaços e à conclusão equivocada de que elas são caracterizadas apenas por traços virtuosos, democráticos e igualitários. Pelo contrário. Da mesma maneira que seria equivocado ver na "esfera pública burguesa" apenas um espaço constituído pela seletividade e pela exclusão - deixando de perceber suas complexidades, bem como suas potencialidades inclusivas e emancipatórias -, é igualmente errôneo atribuir apenas virtude às "esferas públicas subalternas", que na maior parte das vezes são atravessadas por práticas e discursos autoritários e preconceituosos, como, na verdade, ocorre em todos os espaços e organizações coletivas da sociedade. Mas, apesar desses limites e contradições, as "esferas públicas subalternas" não apenas existem - e é fundamental reconhecer suas existências, e compreender suas dinâmicas e suas potencialidades como espaços de conformação de redes de solidariedade social -, mas, conforme destacado por Nancy Fraser (1992), são fundamentais no sentido de ampliarem o espaço discursivo, sobretudo em sociedades tão estratificadas e marcadas por desigualdades estruturais como a brasileira. 


\section{Conclusão}

A despeito de todas as dificuldades impostas pela pandemia, o Brasil tem testemunhado ao longo dos últimos meses a proliferação de diferentes redes de solidariedade social, impulsionadas sobretudo "por baixo", nas periferias e favelas do país. Como procurei destacar na primeira parte deste artigo, experiências como aquelas voltadas para o enfrentamento comunitário do coronavírus, para a arrecadação e distribuição de alimentos a pessoas em condições de vulnerabilidade social, bem como para a organização coletiva dos trabalhadores do mercado informal, sobretudo de entregadores de aplicativos, evidenciam que, não obstante a hegemonia do individualismo e do egoísmo, é possível perceber na sociedade brasileira setores que se organizam, que se associam e se mobilizam, constituindo formas diversas de cooperação e redes de solidariedade social repletas de potencialidades.

Essas experiências societais, que se configuram como manifestações concretas ou embriões em potencial de "esferas públicas subalternas", contribuem não apenas para a problematização do "mito do insolidarismo social" no Brasil - ao evidenciarem as capacidades organizativas, cooperativas e associativas de diferentes setores da sociedade brasileira -, mas têm também a potencialidade de se constituírem como espaços importantes e efetivos de resistência política. Diante de uma conjuntura marcada por índices alarmantes de desemprego e de desigualdade social, e por um cenário atravessado pelo aumento da fome no país, essas redes de solidariedade social contribuem para a organização coletiva de diferentes setores, além de darem maior visibilidade a determinadas agendas na esfera pública, transformando temáticas como as da desigualdade, da fome e da informalidade do mercado de trabalho em "problemas públicos" (GUSFIELD, I98I), o que demanda, em consequência, respostas mais concretas por parte dos poderes públicos.

Um dos maiores desafios que se colocam na atual conjuntura do país se relaciona à necessidade de um maior diálogo e uma articulação mais orgânica entre as "esferas públicas subalternas" e a "esfera pública formal", em especial com os partidos políticos progressistas, que têm condições mais concretas de fazerem com que essas experiências sejam potencializadas, colaborando com projetos mais estruturais e de mais largo alcance de transformação social. A criação do Dia Estadual de Mobilização para Enfrentamento da Covid-I9 e seus Impactos nas Favelas e Periferias, no Rio de Janeiro, bem como a organização do projeto das Cozinhas Solidárias, em diferentes cidades do país, são iniciativas importantes que sinalizam para as possibilidades de que essas redes de solidariedade social se transformem mais efetivamente em espaços de resistência política. 


\section{Agradecimentos}

Agradeço aos professores Marcelo Burgos e Maria Sarah da Silva Telles pelo convite para a submissão deste artigo à revista Desigualdade \& Diversidade. Alguns dos argumentos desenvolvidos foram originalmente apresentados nas Jornadas de Resistência: Solidariedade e Resistência, em abril de 202I, sob a coordenação de Luiz Werneck Vianna, Marcelo Burgos e Maria Alice Rezende de Carvalho. A eles, também, estendo meus agradecimentos pela oportunidade e pelo diálogo.

\section{Referências}

CALHOUN, C. The roots of radicalism: tradition, the public sphere, and early nineteenth century social movements. Chicago: The University of Chicago Press, 2012.

CHALHOUB, S.; SILVA, F. T. Sujeitos no imaginário acadêmico: escravos e trabalhadores na historiografia brasileira desde os anos 1980. Cadernos Arquivo Edgard Leuenroth, Unicamp, v. I4, p. II-50, 2009.

ELLEY, G. Nations, publics and political cultures: placing Habermas in the nineteenth century. In: CALHOUN, C. (Ed.). Habermas and the public sphere. London: MIT Press, I992. p. 289-339.

FRASER, N. Rethinking the public sphere: a contribution to the critique of actually existing democracy. In: CALHOUN, C. (Ed.). Habermas and the Public Sphere. London: MIT Press, 1992.p. IO9-I42.

GINZBURG, C. O queijo e os vermes: o cotidiano e as ideias de um moleiro perseguido pela Inquisição. São Paulo: Companhia das Letras, 1998.

GUSFIELD, J. The culture of public problems: drinking-driving and the symbolic order. Chicago: University of Chicago Press, I98I.

HABERMAS, J. Mudança estrutural da esfera pública. São Paulo: Editora Unesp, 2014.

LANDES, J. Women and the public sphere in the age of the French Revolution. New York: Cornell University Press, 1988.

NEGT, O.; KLUGE, A. Public sphere and experience: toward an analysis of the bourgeois and proletarian public sphere. Minneapolis: University of Minnesota Press, 1993.

PERLATTO, F. Esferas públicas no Brasil: teoria social, públicos subalternos e democracia. Curitiba: Appris Editora, 2018.

PERLATTO, F. Seletividade da esfera pública e esferas públicas subalternas: disputas e possibilidades na modernização brasileira. Revista de Sociologia e Política, v. 23, p. I2 I-I45, 2015. PUTNAM, R. Comunidade e democracia. A experiência da Itália moderna. Rio de Janeiro: FGV, 1996. 
SPIVAK, G. Can the subaltern speak? In: NELSON, C.; GROSSBERG, L.(Eds.). Marxism and the interpretation of culture. Champaign: University of Illinois Press, 1988. p. 27I-313.

SQUIRES, C. Rethinking the black public sphere: an alternative vocabulary for multiple publics. Communication Theory, v. I2, n. 4, p. 446-468, 2002.

WARNER, M. Publics and counterpublics. New York: Zone Books, 2002. 